\title{
Boswellia Derivates and Rehabilitation Program in Knee Osteoarthritis Patients
}

\author{
RODICA TRAISTARU1\#, DRAGOS OVIDIU ALEXANDRU2*, DIANA KAMAL³, KAMAL CONSTANTIN KAMAL 4\#, \\ OTILIA CONSTANTINA ROGOVEANU ${ }^{1 *}$, PARASCHIVA POSTOLACHE ${ }^{5}$ \\ ${ }^{1}$ University of Medicine and Pharmacy of Craiova, Physical and Rehabilitation Medicine Department, 2-4 Petru Rares Str., 200349, \\ Craiova, Romania \\ 2 University of Medicine and Pharmacy of Craiova, Department of Medical Informatics and Biostatistics, 2-4 Petru Rares Str., \\ 200349, Craiova, Romania \\ ${ }^{3}$ Medical Clinic Elga, Craiova, 2 Mihai Eminescu Str., 200131, Craiova, Romania \\ ${ }^{4}$ University of Medicine and Pharmacy of Craiova, Family Medicine Department, 2-4 Petru Rares Str., 200349, Craiova, Romania \\ ${ }^{5}$ Grigore T. Popa University of Medicine and Pharmacy, Faculty of Medicine, 1st Medical Department, Universitatii Str. 16, 700115, \\ lasi, Romania
}

In the presentstudy, we aim to highlight the role of Boswellia derivates in the rehabilitation of the clinical and functional status of patients with knee osteoarthritis. Probably, the judiciously association between herbal products and rehabilitation methods (ultrasound and physical exercise) will give the optimal healthcare for this type of patients.

Keywords: knee osteoarthritis, Boswellia derivates, rehabilitation program

Osteoarthritis (OA), a painful chronic disease affecting the joint cartilage, subchondral bone, joint capsule and synovial, is one of the most common causes of physical disability [1]. The joint most commonly affected by OA is the knee - one of the pivots of the lower driveline with human specific purpose, orthostatic posture and walking. Knee OA is a major social and health problem and a cause of disability among the aging population $[2,3]$.

OA has a multifactorial aetiology and is characterized by a disrupted state of physical and mental wellbeing of the patient. Its pathogenesis includes mechanotransduction, the interplay between metalloproteases (MMP3, MMP13), protease inhibitors and cytokines on cartilage degradation and mechanisms of cartilage repair $[2,4]$. Cytokines (especially interleukin-1 and tumour necrosis factor $\alpha$ ) can promote articular cartilage extracellular matrix protein degradation or synergize with other cytokines to amplify and accelerate cartilage destruction $[4,5]$. Recently, other cytokines were also identified as being involved in the progressive breakdown of articular cartilage. Transcription factor hypoxia-inducible factor- $2 \alpha$ (HIF-2 $\alpha$ ), which is highly enhanced in $\mathrm{OA}$ cartilage, has been shown to activate catabolic metalloproteinases (MMP) including MMP-13 and promote chondrocyte apoptosis [6, 7]. Anabolic cytokines, including transforming grow th factor-beta (TGF- $\beta$ ), insulin-like growth factor-1 (IGF-1), and fibroblast growth factor-2 (FGF-2), have been characterized as potential chondroprotective agents [5].

Medical care of patients with osteoarthritis is provided by a multidisciplinary team and may be challenging because of the presence of co-morbidities that coexist with $O A$. The Technical Expert Panel of revised ACR guidelines strongly recommends that all patients with symptomatic knee OA be enrolled in an exercise program and the use of topical rather than oral NSAIDs [6]. Long term use of NSAIDs has been found to associate with enhanced risk for gastrointestinal bleeding, hypertension, congestive heart failure and renal insufficiency, among other adverse effects, so effective and safer alternative treatments for OA are urgently needed [9-11]. In the last decades, it was mentioned in medical literature the herbal care for $O A$ patients. This type of treatment is in accordance with actual mentioned challenges in treating $O A$, especially in elderly patients [12].

One type of Boswellia derivates are manufactured by Himalaya Herbals a company based in India, endorsed by doctors worldwide and used by customers in over 60 countries. This herbal product made up of several indigenous plants which are well known in Indian medicine is used in osteoarthritis patient in two forms - topical and tablet, since forty years ago $[13,14]$.

\section{Experimental part \\ Hypothesis}

In the present study, we aim to highlight the role of Boswellia derivates tablets in the rehabilitation of the clinical and functional status of patients with knee $O A$. Probably, the judiciously association between herbal products and rehabilitation methods (ultrasound and physical exercise) will give the optimal healthcare for this type of patients.

\section{Patients and methods}

We conducted our observational study during the period May 2017 - November 2017 in the Rehabilitation Department of the Filantropia Hospital Craiova. Our research was performed on 70 patients, all diagnosed with knee osteoarthritis. The study was approved by the institutional ethics review committee. The inclusion criteria taken into account were: patients diagnosed with primitive osteoarthritis according to the American College of Rheumatology, criteria also accepted in our country; at least 15 years of disease progression; painful knee for a period of $48 \mathrm{~h}$ after physical activity; absence of knee injuries at least 6 months before; compliance with physical exercise during the healthcare program.

We completed an initial etiopathogenic, clinical, laboratory (laboratory screening, imaging examination radiography and ultrasound for evidencing joint effusion 
and synovial reaction) and functional assessment. For a functional assessment, we used:

-the VAS - Visual Analogue Scale ( $0=$ absence of pain and $10=$ maximum pain score),

-the WOMAC scale to assess the impact of disease in performing activities of daily living $(0=$ maximum functional status and $96=$ minimum, with maximum disruption of daily activities),

-the Lequesne Functional Index to assess the effectiveness of therapeutic interventions (total index $0=$ none disability, $1-4=$ mild disability, $5-7=$ moderate disability, $8-10=$ severe disability, $11-13=$ very severe disability and $>=14$ extremely severe disability).

Evaluation of patients was carried out in three stages initial (T1), after 3months (T2) - during which an in-hospital program of rehabilitation was conducted, and after a further 3 months (T3) in an outpatient setting. The healthcare objectives were: painful status control; controlling the inflammatory process; regaining stability and mobility of the knee and keeping the knee functional in the biomechanical structure of the limb; correcting the abnormal walking scheme, with recovery of normal walking; regaining motor control, optimal knee function; maintain the quality life of patient.

The rehabilitation program was complex, based on nonsurgical measures and included:

-non-pharmacological measures - educational, dietary and hygienic, posture, physical therapy massage and kinetic measures;

- pharmacological measures - Boswellia derivates (Rumalaya Forte) / 2 tablets per day were given for 3 months period.

Statistical analysis was performed using Microsoft Excel (Microsoft Corp., Redmond, WA, USA), together with the XLSTAT add-on for MSExcel (AddinsoftSARL, Paris, France) and IBM SPSS Statistics 20.0 (IBM Corporation, Armonk, NY, USA) for processing the data. Data was recorded using Microsoft Excel files, then it was statistically analyzed to find relationship between clinical and laboratory parameters of patients. We used Z test for proportions to investigate the statistical significance of the difference between the frequency $f$ of binary variables in general population and the observed frequency $p$ in our sample group. Because the study involved numerical comparisons between 3 sets of data from the same patients, recorded during 3 different visits, that did nothave normal (Gaussian) distributions, we used the median, quartiles and minimummaximum to describe the numerical data, and the nonparametric Friedman test, followed by post-hoc comparisons to detect significant differences between pairs of groups. To test the relationships between changes in the analyzed parameters we used Spearman's correlation coefficient.

\section{Results and discussions}

This is the first clinical study in Romania to evaluate the efficacy of one type of Boswellia derivates in knee OA patients. Our study confirms the antiarthritic activity of this herbal product, where Boswellia serrata, Commiphora wightii and Glycyrrhiza glabra act synergistically, to reduce inflammation and pain. None of our patients reported any serious adverse effects during the study period of 6 months. There was no alteration in the laboratory parameters in patients on Boswellia derivates. The weakness of our study is the lack of a control group to receive placebo, a difficult aspect in rehabilitation medicine. For the study pathology, there is a great difference between the prevalence in women and men - the percentages for the study group compared to the general population distribution in Romania hold a highly significant difference ( $Z$ test $p<0.001$ ), as there are $51.4 \%$ women and $48.6 \%$ men in Romania. The differences concerning the area of residence are not significant ( $Z$ test $p=0.503$ ) - Romania's distribution is $54 \%$ urban, $46 \%$ rural (table 1 ).

Comparing the values recorded for the flexion angle among the three visits (table 2), we observe a steady increase in the values, the overall differences being highly significant (Friedman $p<0.001$ ). Performing post-hoc analysis, we found the values from the second visit to be greater than the initial values, and the values form the last visit being significantly greater than the intermediate values (fig. 1).

Analyzing the visual-analog scale recordings ( fig. 2), we found highly significant differences among the three visits,

Table 1

CHARACTERISTICS OF THE STUDIED PATIENTS

\begin{tabular}{|l|l|l|l|l|l|l|}
\hline Biographic data & \multicolumn{1}{l|}{ Total } \\
\hline Gender & 57 Women $=81.43 \%$ & \multicolumn{1}{l|}{$13 \mathrm{Men}=18.57 \%$} & 70 \\
\hline Residence & 35 Urban $=50 \%$ & $35 \mathrm{Rural}=50 \%$ & 70 \\
\hline Age & $40-49$ years & $50-59$ years & $60-69$ years & $70-79$ years & $80-89$ years & 70 \\
\hline \\
\hline
\end{tabular}

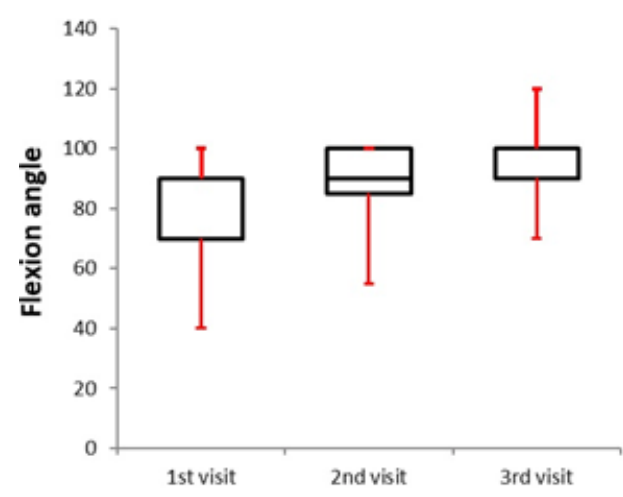

Fig. 1.Comparison of flexion angle values among the three visits

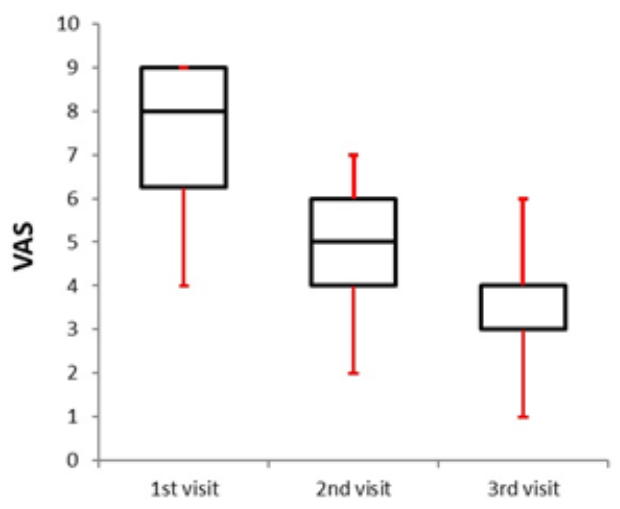

Fig. 2. Comparison of VAS values among the three visits 
the values decreasing over time (Friedman $p<0.001$ ); the post-hoc analysis showed the values from the first visit being lesser than the values form the second visit, which were significantly lesser than the values from the third visit.

The finding for the WOMAC scale values (fig. 3) and the Lequesne functional index values (fig. 4) are similar to those for VAS, showing a highly significant decrease over time (Friedman $p<0.001$ ) (table 2).
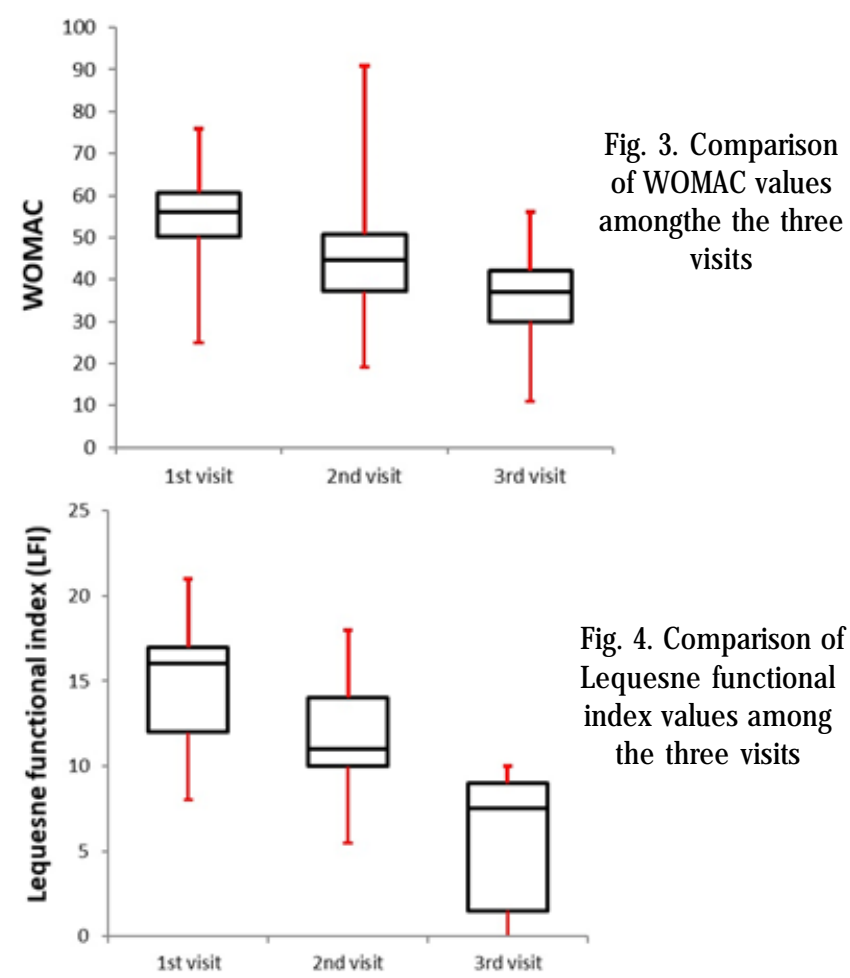

Fig. 4. Comparison of Lequesne functional index values among the three visits

Analyzing the correlation (table 2) between the increase in flexion angle and decrease of the perceived pain or discomfort in performing day to day functions, using Spearman's rho correlation coefficient, we found Lequesne functional index to show the greatest correlation to flexion angle $(\rho=-0.388)$ (fig. 5), followed by WOMAC scale ( $\rho=$ -0.308 ) (fig. 6) and VAS ( $\rho=-0.273$ ) (fig. 7).

Reviewing the literature shows that there are numerous clinical benefits of treatment with Boswellia derivates in knee OA patients, without age limits and supervised rehabilitation program. Our observational study was performed taking into consideration an association between natural treatmentand rehabilitation program. This

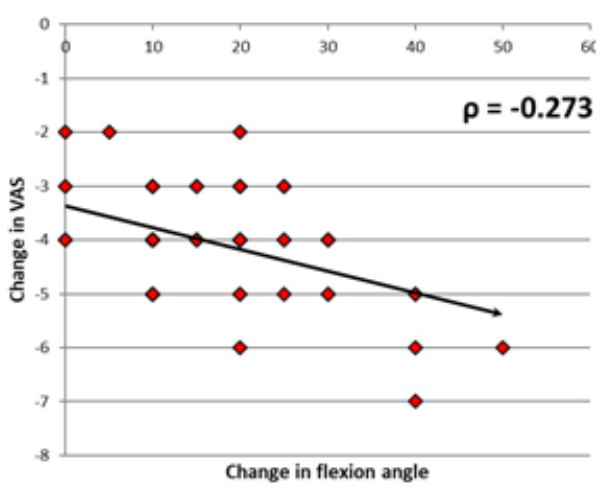

Fig. 5.Correlation between flexion angle changes and VASchanges during the study

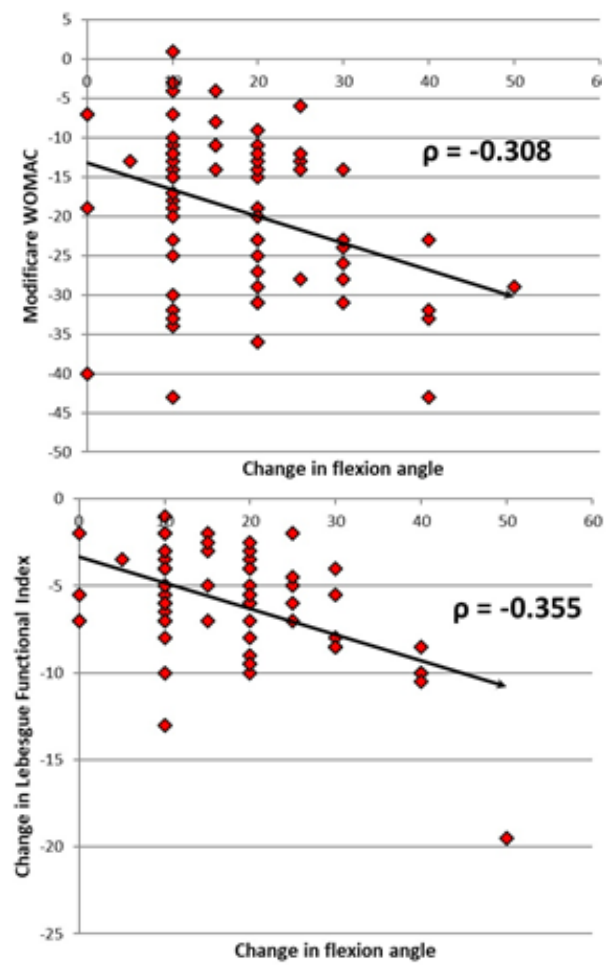

Fig. 6. Correlation between flexion angle changes and WOMAC changes during the study

Fig. 7. Correlation between flexion angle changes and LFI changes during the study

herbal product shows significant improvement of symptoms like pain, swelling, joint malfunction and mobility in patients of $\mathrm{OA}$ and does not produce any serious side effects. Since the patients have frequent acute exacerbations of chronic osteoarthrosis at frequent intervals, it requires symptomatic treatment from timetime. Although, it has no toxic effect [14].

\begin{tabular}{|c|c|c|c|c|c|c|}
\hline \multirow{2}{*}{\begin{tabular}{|l} 
Variable \\
Parameter \\
\end{tabular}} & \multicolumn{3}{|c|}{ Flexion angle } & \multicolumn{3}{|l|}{ VAS } \\
\hline & $\mathrm{Tl}$ & $\mathbf{T 2}$ & T3 & Tl & T2 & T3 \\
\hline Minimum & 40 & 55 & 70 & 4 & 2 & 1 \\
\hline 1st Quartile & 70 & 85 & 90 & 6.25 & 4 & 3 \\
\hline Median & 90 & 90 & 100 & 8 & 5 & 4 \\
\hline 3rd Quartile & 90 & 100 & 100 & 9 & 6 & 4 \\
\hline Maximum & 100 & 100 & 120 & 9 & 7 & 6 \\
\hline Variable & \multicolumn{3}{|c|}{ WOMAC } & \multicolumn{3}{|c|}{ Lequesne functional index } \\
\hline Parameter & Tl & T2 & T3 & $\mathrm{Tl}$ & $\mathrm{T} 2$ & T3 \\
\hline Minimum & 25 & 19 & 11 & 8 & 5.5 & 1.5 \\
\hline 1st Quartile & 50.25 & 37.25 & 30 & 12 & 10 & 7.5 \\
\hline Median & 56 & 44.5 & 37 & 16 & 11 & 9 \\
\hline 3rd Quartile & 60.75 & 50.75 & 42 & 17 & 14 & 10 \\
\hline Maximum & 76 & 91 & 56 & 21 & 18 & 16.5 \\
\hline
\end{tabular}

Table 2

MEDIAN AND SPREAD INDICATORS FOR THE STUDY VARIABLES 
Also the combination of herbal compounds of this type of Boswellia derivates was different upon time, all combinations and herbal plants claimed to have analgesic and anti-inflammatory actions, besides antispasmodic activity and antiseptic action. Some constituents stimulate uric acid excretion; prevent gouty arthritis, osteoporosis and degenerative changes in the joints [15]. Clinical efficacy of herbal product - an Ayurvedic preparation is comparable to that of the commonly used drugs Diclofenac sodium and Ibuprofen. The analgesic effect of Boswellia derivates is comparable to that of Diclofenac and Ibuprofen $[15,16]$. The combination of several herbs that compound our studied natural product is changing in time.

Today it is from the renowned Himalaya Herbals products have been researched clinically and standardized to guarantee bioequivalence. Himalaya Herbal Healthcare uses chromatographic fingerprinting, one of the most sophisticated standardization techniques, to ensure consistent quality and performance [17]. For the last two decades, formulation of studied product contains six herbal extracts as active ingredients: Alpinia Galanga (Rasna) 70 mg, Boswellia Serrata (Boswellia / Shallaki) 240 mg, Commiphora Wightii (Indian Bedellium / Guggul) 200 mg, Glycyrrhiza Glabra (Licorice / Yashti madhu) 70 mg, Tinospora Cordifolia (Tinospora Gulancha / Guduchi) $60 \mathrm{mg}$ and Tribulus Terrestris (Small caltrops / Gokshura) $60 \mathrm{mg}$, like in our study. These ingredients have shown to have anti-inflammatory, anti-arthritic, immunomodulatory, muscle relaxant and analgesic activities [18]. This type of Boswellia derivates tablets seem to be safe and effective drugs for treatment of OA-patients [19]. [20].

No side effects were reported by any of the patients

Boswellia serrata is the primary and the most important constituent of studied natural product, which has been historically used in the treatment of OA. Boswellia serrata gum resin extract (BSE) containing boswellic acids (BAs) as the main bioactive principles. 3-0-acetyl-11-ketobetaboswellic acid (AKBA) is the most active component. These extracts have demonstrated their anti-inflammatory role, with good management of musculoskeletal pain and inflammation, due to several mechanisms of action including inhibition of inflammatory mediators, prevention of decreased glycosaminoglycan synthesis, improved blood supply to joint tissues [10, 21, 22].

All these medicinal plants may inhibit inflammatory mediators and interact with various cytokines, at least under experimental conditions. The mechanism of action of the oral herbal medicines is likely to be broader than that of non-steroidal anti-inflammatory drugs [23-27]. Although their mechanisms of action have not yet been elucidated in full detail, interactions with mediators of inflammation and cartilage destruction provide a rationale for using them to treat $O A$ complaints. The active principle of a medicinal plant product is the sum of all ingredients that produce the medicinal action. Despite their advantages, herbal treatments in general, and studied tablet in special, raise several concerns, such as drugherbal interactions, low bioavailability, insufficient regulatory guidelines at national and international levels [28].

\section{Conclusions}

Taken daily, this type of Boswellia derivates product - a real natural product, without side effects - has demonstrated positive results in relieving pain due to osteoarthritis, promoting normal strength and flexibility of muscle, with enhancing the quality of life in patients with knee OA.

Physiotherapy in association with studied herbal product represents the best drug for elderly patients with osteoarthritis, with a favorable impact on the whole body and wellbeing.

In the next years, the controlled studies may be conducted to evaluate the complex role of various Boswellia derivates in the complete management of $O A$ patient.

\section{References}

1.HINMAN, R.S., HUNT, M.A., CREABY, M.W., WRIGLEY, T., MCMANUS, F.J ., BENNELL, K.L., Arthritis Care Res., 62, nr. 8, 2010, p 1190-1193 2.ROMAN, M.D., FLEACA, R.S., BOICEAN, A., BRATU, D., BIRLUTIU, V., RUS, L.L., TANTAR, C., CERNUSCA MITARIU, S.I., Rev. Chim.(Bucharest), 68, no. 6, 2017, p 1242-1244

3.TRAISTARU, R., POPESCU, R., GRUIA, C., ROGOVEANU, O., Romanian J ournal of Morphology and Embryology, 54, nr. 3, 2013, p $593-601$

4.KOBAYASHI, M., SQUIRES, G.R., MOUSA, A., TANZER, M., et.al., Arthritis Rheum., 52, nr.1, 2005, p 128-135

5.MALEMUD, C.J ., Drugs \& Aging, 27, 2010, p 95-115

6.BOSTAN, L., MUNTEANU, F., POPA, M.I., VERESTIUC, L., Rev. Chim., 61, no. 12, 2010, p. 1235-1238

7.VAN DEN BERG, W.B., Osteoarthritis and Cartilage, 19, 2011, p 338341

8.HOCHBERG, M.C., ALTMAN, R. D., APRIL, K.T., BENKHALTI, M., et.al., Arthritis Care \& Research, 64, nr. 4, 2012, p 465-474

9.ORBAN, H., CIRSTOIU, C., ZAHARIA, C., CINCU, C., Rev. Chim.(Bucharest), 59, no. 6, 2008, p. 688-690

10.SENGUPTA, K., KRISHNARAJU, A.V., VISHAL, A.A., MISHRA, A., et.al., International J ournal of Medical Sciences, 7, nr. 6, 2010, p 366-377

11.KIM, J.K., PARK, S.W., KANG, J.W., KIM, Y.J ., et.al., Evid Based Complement Alternat Med, 2012: 730907, 2012

12.*** www.albertadoctors.org/DUEQuarterly/index

13.TANEJA, D.K., CHARA, G.U., The Antiseptic, 72, nr. 10, p 527

14.BISWAJ IT, S., BANERJ EE, S.K., De MAZUMDER, N., SARKAR, N., et.al., Ind. Med. J., 74, nr. 11, 1980, p 151

15.RASTOGI, S., BANSAL, R., KULKARNI, K.S., The Antiseptic, 98, nr. 5, 2001, p 172-173

16.SINGH, U., KISHORE, K., SETH, S.D., IJ PMR, 8 -9, April, p 1997 -98 17.*** http://himalayawellness.com/index.htm

18.CHANDANWALE, A.S., KULKARNI, K.S., Medicine Update, 10, nr. 9, 2003, p 23-26

19.KESSLER,C.S., PINDERS, L., MICHALSEN, A., CRAMER, H., Rheumatol Int., 35, nr. 2, 2015, p 211-32

20.RASTOGI, S., SIVARAMAN, S.T, KULKARNI, K.S., Orthopaedics Today, V, nr. 1, 2003, p $63-65$

21.AKHTAR, N., MILLER, M.J., HAQQI, T.M., BMC Complement Altern Med, 11, 2011, p 66

22.ABDEL-TAWAB, M., WERZ, O., SCHUBERT-ZSILAVECZ, M., Clin Pharmacokinet., 50, 2011, p 349-69.

23.BERBECE, I.S., PLESEA CONDRATOVICI, A., PAVEL, A., GRIGORE, C., Rev. Chim.(Bucharest), 68, no. 5, 2017, p 1073-1076

24.PHITAK, T., CHOOCHEEP, K., POTHACHAROEN, P., POMPIMON, W., et.al., Phytochemistry, 70, 2009, p 237-243

25.ZHU, W., DU, Y., MENG, H., DONG,Y., LI, L., Chemistry Central Journal,11, 2017, p 60

26.BABURAO, B., RAJYALAKSHMI, G., VENKATESHAM, A., KIRAN, G., et.al., Int. J. Chem. Sci., 16, nr. 2, 2009, p 209-218

27.J ECAN, R. C., NICOLAU, A., FLORESCU, P. I., ARDELEANU, V., BERBECE, I.S., Mat. Plast., 54, no. 1, 2017, p. 88-90

28.POSADZKI, P., WATSON, L., ERNST, E., Eur. J. Clin. Pharmacol, 69, 2013, p 295-307

$\overline{\text { Manuscript received: } 14.05 .2018}$ 